Keywords: Mechanical Properties, Type 304L Stainless Steel, Type 316L Stainless Steel, Type 21-6-9 Stainless Steel, Hydrogen

Embrittlement, J-Integral, Helium

Embrittlement

Retention: Permanent

\title{
2012 Accomplishments - Tritium Aging Studies on Stainless Steels
}

\author{
MICHAEL J. MORGAN \\ Materials Science and Technology
}

Publication Date: January 2013

This document was prepared in conjunction with work accomplished under Contract No. DE-AC0908SR22470 with the U. S. Department of Energy

Savannah River National Laboratory Savannah River Nuclear Solutions, LLC Aiken, SC 29808

Prepared for the U.S. Department of Energy under

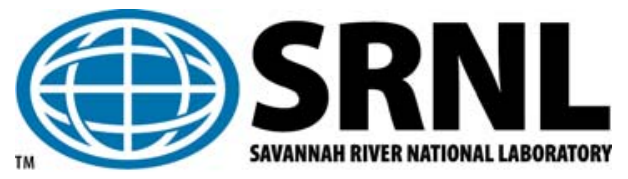
contract number DE-AC09-08SR22470. 


\section{DISCLAIMER}

This work was prepared under an agreement with and funded by the U.S. Government. Neither the U.S. Government or its employees, nor any of its contractors, subcontractors or their employees, makes any expressed or implied:

1. Warranty or assumes any legal liability for the accuracy, completeness, or for the use or results of such use of any information, product, or process disclosed; or

2. Representation that such use or results of such use would not infringe privately owned rights; or 3. Endorsement or recommendation of any specifically identified commercial product, process, or service.

Any views and opinions of authors expressed in this work do not necessarily state or reflect those of the United States Government, or its contractors, or subcontractors.

\section{Printed in the United States of America}

Prepared for U.S. Department of Energy 
2012 Accomplishments - Tritium Aging Studies on Stainless Steels

List of Tables

I. Summary 1

II. Introduction $\quad 1$

III. Fabrication And Tritium Charging Of Samples For 2 Future Tritium Aging Studies

IV. Experimental Plan For Measuring Cracking Thresholds 7 Of Tritium-Charged-And-Aged Steels In High Pressure Hydrogen Gas

V. Tritium Contents For Laboratory Inventory 11 Requirements And Environmental Release Estimates

VI. Cracking Thresholds And Fracture Toughness 13 Properties Of Tritium-Charged-And-Aged Stainless Steels

VII. The Effects Of Hydrogen, Tritium, And Heat Treatment 16 On The Deformation And Fracture Toughness Properties Of Stainless Steels

VIII. Summary

IX. References 


\section{List of Figures $\quad$ Page}

Figure 1. Wedge Opening Load Specimen.

Figure 2. Wedge Opening Load Specimen (Detail). 10

Figure 3. Wedge-Opening-Load Specimen Showing Allen Wrench, Bolt for Loading the Specimen, and Grips for Unloading the Specimen on Mechanical Test Machine.

Figure 4. Wedge-Opening-Load Specimen Showing Bolt Loading Technique with Allen Wrench, COD Gage, and Leads For Crack Length Measurement.

Figure 5. Seventy-Five Arc-Shaped Stainless Steel Coupons (on left)

Stacked onto Tritium Charging Assembly in Three Columns (on right).

Figure 6. Tritium Charging Assembly Showing Top and Bottom Caps and Six Rods.

Figure 7. Effect of Decay Helium Content on Sustained-Load Cracking Thresholds and Rising Load Fracture Toughness Values.

Figure 8. Figure 2. 2012 International Hydrogen Conference Presentation Charged-and-Aged Stainless Steels”.

Figure 9. Hydrogen-Precharged Steels Given a Prior Heat Treatment at 873 K Show Similar Fracture Toughness Reductions As TritiumPrecharged Samples.

Figure 10. Microstuctures of (a) As Forged Steel (optical image); (b) Heat-Treated for $10 \mathrm{Min}$. at $873 \mathrm{~K}$ (Scanning Electron Microscope Image); and (c) Heat Treated for 10 Hours at 873 K (SEM Image).

Figure 11. 2012 International Hydrogen Conference Presentation on "The Effects of Hydrogen and Tritium and Heat Treatment on the Deformation and Fracture Toughness Properties of Stainless Steels. 


\section{List of Tables}

Table I - SRNL Data Sheet Charging Conditions Tritium Charging Run 2012-1.

Table II - Samples Charged During Tritium Charging Run 2012-1

Table III - SRNL Data Sheet Charging Conditions Tritium Charging Run 2012-2.

\section{Page}

3

4

5

6 
SRNL-STI-2013-00048

\section{Accomplishments - Tritium Aging Studies on Stainless Steels}

\section{SUMMARY}

This report summarizes the research and development accomplishments during FY12 for the tritium effects on materials program. The tritium effects on materials program is designed to measure the long-term effects of tritium and its radioactive decay product, helium-3, on the structural properties of forged stainless steels which are used as the materials of construction for tritium reservoirs. The FY12 R\&D accomplishments include: (1) Fabricated and Thermally-Charged 150 Forged Stainless Steel Samples with Tritium for Future Aging Studies; (2) Developed an Experimental Plan for Measuring Cracking Thresholds of Tritium-Charged-and-Aged Steels in High Pressure Hydrogen Gas; (3) Calculated Sample Tritium Contents For Laboratory Inventory Requirements and Environmental Release Estimates; (4) Published report on "Cracking Thresholds and Fracture Toughness Properties of Tritium-Charged-and-Aged Stainless Steels"; and, (5) Published report on "The Effects of Hydrogen, Tritium, and Heat Treatment on the Deformation and Fracture Toughness Properties of Stainless Steels". These accomplishments are highlighted here and references given to additional reports for more detailed information.

\section{INTRODUCTION}

Forged stainless steels are used as the materials of construction for tritium reservoirs. During service, tritium diffuses into the reservoir walls and radioactively decays to helium-3. Tritium and decay helium cause a higher propensity for cracking which could lead to a tritium leak or delayed failure of a tritium reservoir. The factors that affect the tendency for crack formation and propagation include: (a) time of exposure; (b) steel type; (c) steel microstructure; (d) reservoir geometry and gas pressure; and, (e) reservoir residual stresses from welding and manufacturing. Fracture toughness properties are needed for designing tritium reservoirs and evaluating the long-term effects of tritium on their structural properties. These effects are being characterized with the Enhanced Surveillance Campaign Tritium Effects on Materials Program using the plan described in Reference 1. Chiefly, the results are obtained by measuring the effects of tritium on the tensile and fracture toughness properties of samples fabricated from forgings on pre-charged samples tested in air.

This report describes the FY12 accomplishments for the Tritium Effects on Materials Program. The FY12 R\&D accomplishments include: (1) Fabricated and Thermally-Charged 150 Forged Stainless Steel Samples with Tritium for Future Aging Studies; (2) Developed an Experimental Plan for Measuring Cracking Thresholds of Tritium-Charged-and-Aged Steels in High Pressure Hydrogen Gas; (3) Calculated Sample Tritium Contents For Laboratory Inventory Requirements and Environmental Release Estimates; (4) Published report on "Cracking Thresholds and Fracture Toughness Properties of Tritium-Charged-and-Aged Stainless Steels"; and, (5) Published report on 
"The Effects of Hydrogen, Tritium, and Heat Treatment on the Deformation and Fracture Toughness Properties of Stainless Steels”.

\section{FABRICATION AND TRITIUM CHARGING OF SAMPLES FOR FUTURE TRITIUM AGING STUDIES}

An important FY12 accomplishment was the fabrication and tritium precharging of 150 samples for future tritium aging studies. These samples are part of four new comprehensive experimental research and development programs that are underway for investigating the effects of hydrogen, tritium, and decay helium on the fracture toughness properties of forged stainless steels. The programs and test matrices are described in a recent program plan (1).

These programs are first-of-a-kind because they set out to measure tritium and decay helium effects on the cracking properties of stainless steels using actual tritium reservoir forgings instead of the experimental forgings of past programs. In this way, the properties measured will be nearly identical to actual reservoir properties because the microstructure of the samples will be like that of the forged reservoirs. There are four major programs each designed to measure the effects of a specific forging variable on tritium compatibility.

The programs include three stainless steels, multiple yield strengths, four different forging processes, and four different reservoir forgings. They are entitled: (1) Orientation Effect - Type 316L Cup Forging; (2) Yield Strength Effect - Type 304L Cylindrical Block Forging; (3) Fracture Toughness Variability - Type 21-6-9 Stainless Brick Forging; and (4) Forging Process Effects. The plan describes the goals of each program, lists the sample test matrices and experimental conditions, and reports on initial results (1).

Two tritium charging runs were conducted in FY12 (2-3) by Tritium Programs Operations and Engineering with support by SRNL R\&D Engineering. The tritium fill conditions were designed to saturate the samples with tritium at a nominal pressure of 5000 psia at a temperature of $350 \mathrm{C}$ for two weeks. Table I shows the SRNL Data Sheet for the specific fill conditions that were used to charge the samples in the first run and the samples charged during the run are listed in Table II (2). Likewise, Table III shows the SRNL Data Sheet for the fill conditions that were used during the second run and the samples charged are listed in Table IV (3). 


\section{Table I SRNL DATA SHEET}

\section{CHARGING CONDITIONS TRITIUM CHARGING RUN 2012-1}

\section{FORGING EFFECT SAMPLES}

Document Number: SRNL-L4400-2012-00027 Rev 0

Vessel Serial Number:

02151151-4

Vessel Charge History:

First Use

Charge Type:

Type 1 (C-Shaped Samples)

Total Free Volume, Vessel and Tubing: $\quad 248 \mathrm{cc}$

Acceptable Temperature Range During Fill: $18-28^{\circ} \mathrm{C}$

Target Fill Pressure:

2619 psia

Target Fill Pressure Range:

2609-2629 psia

Heated Vessel Temperature:

$350^{\circ} \mathrm{C} \pm 5^{\circ} \mathrm{C}$

Duration at Temperature and Pressure: 14 Days \pm 8 Hours 
Table II Samples Charged During Tritium Charging Run 2012-1

\section{VESSEL SN 02151151-4 \\ FORGING EFFECT SAMPLES - Stacking Order}

$\begin{array}{lcccccc}\text { Source } & \text { Test Env. } & \text { Material } & \text { ID } & \text { ID } & \text { ID } & \begin{array}{c}\text { Layer in } \\ \text { Rack }\end{array} \\ & & & & & & \\ \text { No Anneal Herf } & \text { Air } & 304 \mathrm{~L} & \text { F16-1 } & \text { F16-5 } & \text { F16-9 } & 25 \\ \text { No Anneal Herf } & \text { Air } & & \text { F71-1 } & \text { F71-5 } & \text { F71-9 } & 24 \\ \text { No Anneal Mech } & \text { Air } & 304 L & \text { M16-1 } & \text { M16-5 } & \text { M16-9 } & 23 \\ \text { No Anneal Mech } & \text { Air } & & \text { M71-1 } & \text { M71-6 } & \text { M71-9 } & 22 \\ \text { No Anneal Hyd. } & \text { Air } & \text { 304L } & \text { Y16-1 } & \text { Y16-5 } & \text { Y16-9 } & 21 \\ \text { No Anneal Hyd. } & \text { Air } & & \text { Y71-1 } & \text { Y71-5 } & \text { Y71-9 } & 20 \\ \text { No Anneal Screw } & \text { Air } & \text { 304L } & \text { S16-1 } & \text { S16-5 } & \text { S16-9 } & 19 \\ \text { No Anneal Screw } & \text { Air } & & \text { S71-2 } & \text { S71-5 } & \text { S71-9 } & 18 \\ & \text { Air } & \text { 304L } & \text { S2A-4 } & \text { S2B-3 } & \text { S2B-5 } & 17 \\ \text { Stage } 2 & & & & & \end{array}$

\section{Sandia Forging Samples}

$\begin{array}{lll} & \text { Air } & \text { 316L } \\ & \text { Air } & \\ & \text { Air } & \\ \text { Cup } & \text { Air } & \\ & \text { Air } & 316 \mathrm{~L} \\ & \text { Air } & \\ & \text { Air } & \\ \text { Stem } & \text { Air } & \\ & \text { H2 } & 316 \mathrm{~L} \\ & \mathrm{H} 2 & \\ & \mathrm{H} 2 & \\ \text { Cup } & \mathrm{H} 2 & \\ & \mathrm{H} 2 & 316 \mathrm{~L} \\ & \mathrm{H} 2 & \\ & \mathrm{H} 2 & \\ & \mathrm{H} 2 & \end{array}$

$\begin{array}{cccc}\text { 26AL6 } & \text { 26AL9 } & \text { 26BL5 } & 16 \\ \text { 26AL5 } & \text { 26AL10 } & \text { 26BL6 } & 15 \\ \text { 26AL4 } & \text { 26BL1 } & \text { 26BL7 } & 14 \\ \text { 26AL3 } & \text { 26BL2 } & \text { 26BL8 } & 13 \\ \text { 26RE3 } & \text { 26RF5 } & \text { 26RC2 } & 12 \\ \text { 26RD4 } & \text { 26RE1 } & \text { 26RF3 } & 11 \\ \text { 26RC5 } & \text { 26RD2 } & \text { 26RE4 } & 10 \\ \text { 26RF1 } & \text { 26RC3 } & \text { 26RD5 } & 9 \\ \text { 26AL13 } & \text { 26AL19 } & \text { 26BL15 } & 8 \\ \text { 26AL14 } & \text { 26AL20 } & \text { 26BL16 } & 7 \\ \text { 26AL15 } & \text { 26BL11 } & \text { 26BL17 } & 6 \\ \text { 26AL16 } & \text { 26BL12 } & \text { 26BL18 } & 5 \\ \text { 26RE8 } & \text { 26RF10 } & \text { 26RC7 } & 4 \\ \text { 26RD9 } & \text { 26RE6 } & \text { 26RF8 } & 3 \\ \text { 26RC10 } & \text { 26RD7 } & \text { 26RE9 } & 2 \\ \text { 26RF6 } & \text { 26RC8 } & \text { 26RD10 } & 1\end{array}$

Rack Info.

Bottom $=1$, Top $=25$

Total Samples: 75 
BLOCK FORGING SAMPLES

Document Number: SRNL-L4400-2012-00027 Rev 0

Vessel Serial Number:

02151151-3

Vessel Charge History:

First Use

Charge Type:

Type 1 (C-Shaped Samples)

Total Free Volume, Vessel and Tubing: $\quad 253 \mathrm{cc}$

Acceptable Temperature Range During Fill: $18-28^{\circ} \mathrm{C}$

Target Fill Pressure:

2619 psia

Target Fill Pressure Range:

2609-2629 psia

Heated Vessel Temperature:

$350^{\circ} \mathrm{C} \pm 5^{\circ} \mathrm{C}$

Duration at Temperature and Pressure: 14 Days \pm 8 Hours 


\section{Table IV Samples Charged During Run 2012-2}

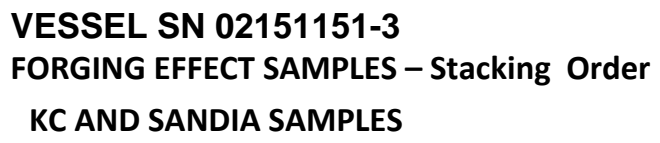

\begin{tabular}{|c|c|c|c|c|c|c|}
\hline Source & Test Env. & Material & ID & ID & ID & Layer in Rack \\
\hline \multicolumn{7}{|l|}{ KCP Remnants } \\
\hline Anneal Herf & Air & $304 \mathrm{~L}$ & AF16-3 & AF16-5 & AF16-7 & 25 \\
\hline Anneal Herf & Air & & AF71-3 & AF71-5 & AF71-7 & 24 \\
\hline Anneal Mech & Air & $304 \mathrm{~L}$ & AM16-3 & AM16-4 & AM16-8 & 23 \\
\hline Anneal Mech & Air & & AM71-3 & AM71-4 & AM71-8 & 22 \\
\hline Anneal Hyd. & Air & $304 \mathrm{~L}$ & AY16-3 & AY16-5 & AY16-7 & 21 \\
\hline Anneal Hyd. & Air & & AY71-3 & AY71-4 & AY71-8 & 20 \\
\hline Anneal Screw & Air & $304 \mathrm{~L}$ & AS16-3 & AS16-4 & AS16-8 & 19 \\
\hline Anneal Screw & Air & & AS71-3 & AS71-4 & AS71-8 & 18 \\
\hline Stage 2 & Air & $304 \mathrm{~L}$ & S2B-1 & S2B-6 & $\mathrm{S} 2 \mathrm{~A}-2$ & 17 \\
\hline \multicolumn{7}{|c|}{ Sandia Forging Samples } \\
\hline \multirow[t]{4}{*}{11459 (LY) } & Air & $304 \mathrm{~L}$ & $59 R C 7$ & 59RD11 & 59RA5 & 16 \\
\hline & Air & & 59RB10 & $59 R C 3$ & 59RD8 & 15 \\
\hline & Air & & 59RA2 & 59RB7 & 59RC12 & 14 \\
\hline & Air & & 59RD5 & 59RA10 & 59RB3 & 13 \\
\hline \multirow[t]{4}{*}{$11460(\mathrm{HY})$} & Air & $304 \mathrm{~L}$ & $60 R C 7$ & 60RD11 & 60RA5 & 12 \\
\hline & Air & & 60RB10 & $60 R C 3$ & 60RD3 & 11 \\
\hline & Air & & 60RA2 & 60RB7 & $60 \mathrm{RC} 12$ & 10 \\
\hline & Air & & 60RD5 & 60RA10 & 60RB3 & 9 \\
\hline \multirow[t]{4}{*}{11459 (LY) } & $\mathrm{H} 2$ & $304 \mathrm{~L}$ & 59RA3 & 59RB8 & $59 R C 1$ & 8 \\
\hline & $\mathrm{H} 2$ & & 59RD6 & 59RA11 & 59RB4 & 7 \\
\hline & $\mathrm{H} 2$ & & 59RC9 & 59RD2 & 59RA7 & 6 \\
\hline & $\mathrm{H} 2$ & & 59RB12 & $59 R C 5$ & 59RD10 & 5 \\
\hline \multirow[t]{5}{*}{$11460(\mathrm{HY})$} & $\mathrm{H} 2$ & $304 \mathrm{~L}$ & 60RA3 & 60RB8 & $60 \mathrm{RC} 1$ & 4 \\
\hline & $\mathrm{H} 2$ & & 60RD6 & 60RA11 & 60RB4 & 3 \\
\hline & $\mathrm{H} 2$ & & 60RC9 & 60RD2 & 60RA7 & 2 \\
\hline & $\mathrm{H} 2$ & & 60RB12 & $60 R C 5$ & 60RD10 & 1 \\
\hline & & & & Rack Info & Bottom $=$ & $=25$ \\
\hline
\end{tabular}

Note: AF16-4, AF71-4 and AY16-4 were changed to - 5 because precracks were too long. Note: AF16-8, AF71-8 and AY16-8 were changed to -7 because precracks were too long. Total samples: 75 
SRNL-STI-2013-00048

\section{EXPERIMENTAL PLAN FOR MEASURING CRACKING THRESHOLDS OF TRITIUM-CHARGED-AND-AGED STEELS IN HIGH PRESSURE HYDROGEN GAS}

Prior experiments and analysis have demonstrated that sustained-load cracking threshold data are needed to conduct fracture mechanics analyses and establish safe operating lifetimes of tritium reservoirs (4-6). Tritium and decay helium reduce the fracture toughness properties of stainless steel and make crack nucleation and propagation easier. Until now, these effects have been characterized in the laboratory by measuring the fracture toughness properties as a function of tritium and decay helium content on samples tested in air. Recent results suggest that stainless steels tested in highpressure hydrogen environments could have lower cracking thresholds than steels precharged with hydrogen and tested in air. A similar result is expected for samples tested in high-pressure tritium environments when compared to tritium pre-charged steels, however, a facility for conducting fracture mechanics tests on radioactive tritium samples is not available at this time.

An experimental concept for acquiring fracture mechanics properties on tritium precharged steels tested in high-pressure hydrogen environments under sustained loads was developed during FY12. The concept is modeled after ASTM E1681 "Standard Test Method for Determining Threshold Stress Intensity Factor for Environmental Assisted Cracking of Metallic Materials” (7) and utilizes bolt-loaded samples and an existing tritium pre-charging facility at SRS. This concept could provide needed sustained-load fracture mechanics data in the short term until a mechanical testing facility is available for conducting rising-load mechanical property and fracture mechanics tests on tritiumcharged-and-aged samples tested in high-pressure hydrogen environments (8).

Cracking threshold experiments on tritium-precharged samples in high-pressure deuterium gas would be conducted in the following way. A wedge-opening load (WOL) compact tension specimen as shown in Figures 1and 2 will be used for the tests. Samples will be fabricated from stainless steel brick forgings (1) with a width of 1 inch and a thickness of .25 inches. The samples will be fatigue pre-cracked and then loaded into a tritium charging vessel like those used for charging the samples in Section III above.

The vessel will then be sealed and pressurized on the tritium loading line in the same way samples have been tritium pre-charged for the prior studies; i.e., the vessel will be pressurized to $5000 \mathrm{psi}$ and held at a temperature of $350^{\circ} \mathrm{C}$ for up to four weeks to saturate the samples with tritium. A two-week longer charge time will be needed to reach saturation because these samples are 0.05 ” thicker than previous samples.

After the tritium pre-charging operation, the vessel will be cooled down and evacuated. The samples will be removed from the vessel and transported to SRNL for freezer storage at $-70 \mathrm{C}$ to minimize tritium off-gassing losses. The samples will be stored and aged for up to five years to build-in helium from tritium. After a set of samples reach the desired helium content from tritium decay, they will be loaded with a bolt to specific crack-opening displacement (COD) level (Figures 3 and 4). The COD will 
correspond to an initial load dervived from the load-COD calibration curve. A potentialdrop system may also be used to monitor crack length during the loading operation.

Identical samples with the desired helium content will be loaded to low, medium, and high levels of COD. These bolt-loaded samples will then be placed back in a tritium charging vessel on the tritium loading line. Each vessel will be able to accommodate about 20 bolt-loaded specimens. The vessel will then be back-filled with high-pressure hydrogen or deuterium gas and then valved off and held at ambient temperature in the loading line glove box for up to three months at pressure. This hold step will provide a high-pressure gas environment around the loaded crack tip in a tritium-precharged sample with a given helium content.

After three months, the vessel will evacuated and the samples recovered and transferred to SRNL. The samples will be heat-tinted in a furnace to mark the exent of any crack growth, and unloaded in a mechanical testing machine while measuring the current load on the bolt. Again, a potential drop system may be used to measure any crack growth that may have occurred during the high-pressure exposure.The load on the bolt and the measured crack length at the end of the hold period will be used to establish the cracking threshold at the current helium level in the sample.

For samples that cracked during the hold period, new samples will be loaded using low, medium, and high loads, but now lower than the values that caused cracking in the earlier experiment. In this way, a more precise cracking threshold value will be found. Conversely, if samples do not crack during the defined hold period, a safe operating load is established. Subsequent samples will be loaded at higher loads to establish the cracking threshold.

More detailed procedures will be developed during FY13 using hydrogen exposures on non-charged samples. 


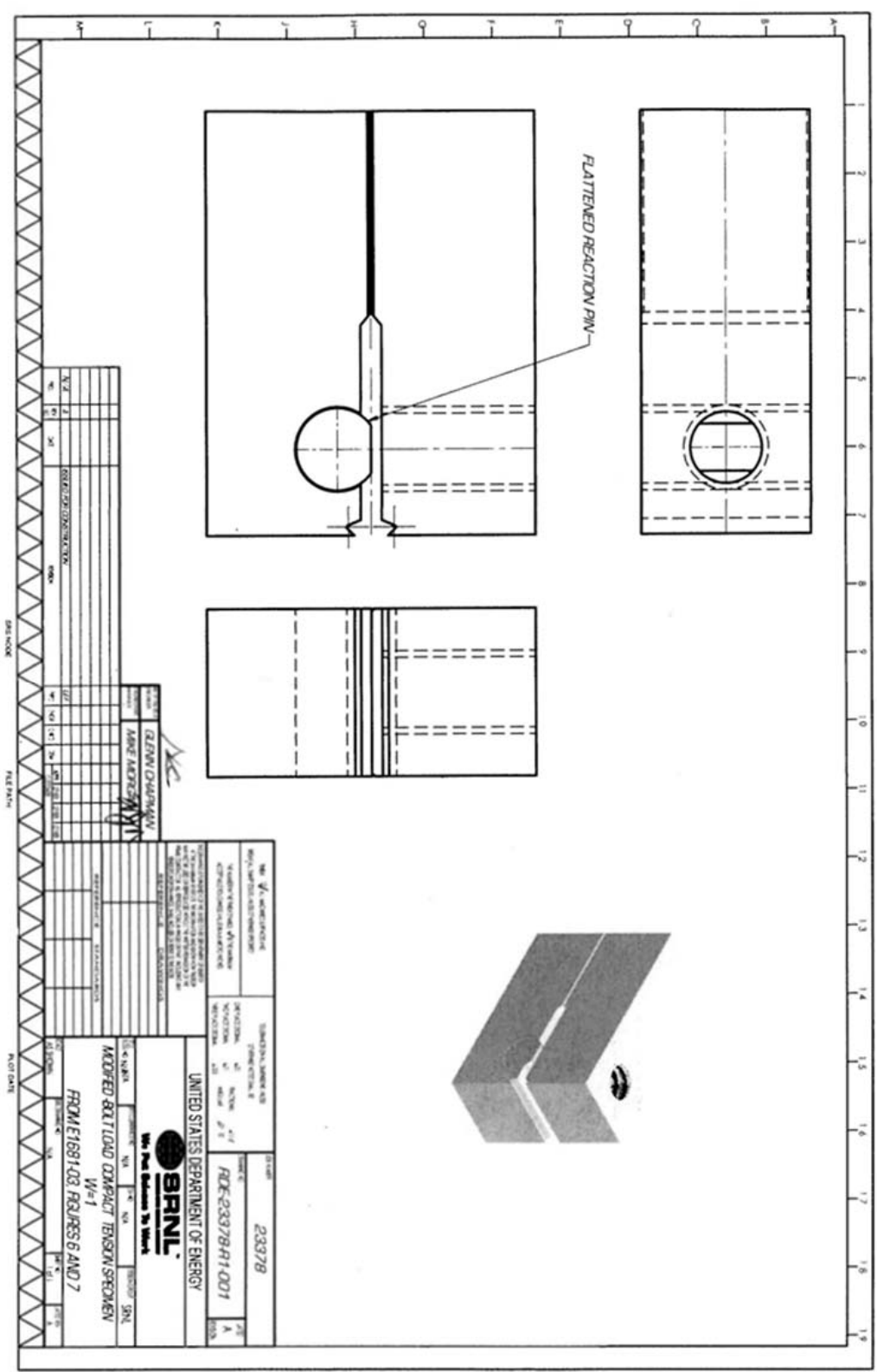

Figure 1. Wedge-Opening-Load Specimen. 


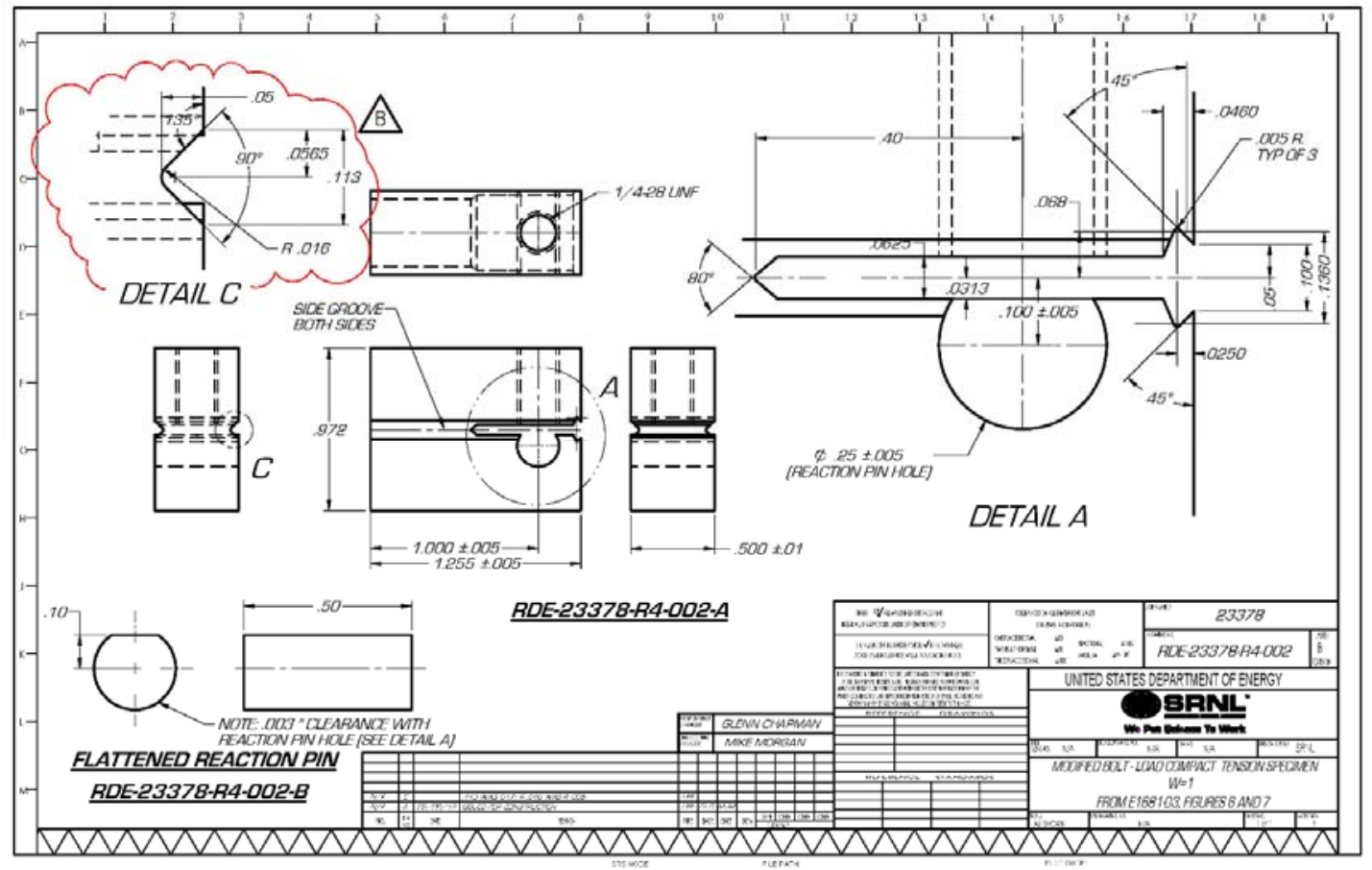

Figure 2. Wedge Opening Load Specimen (Detail).

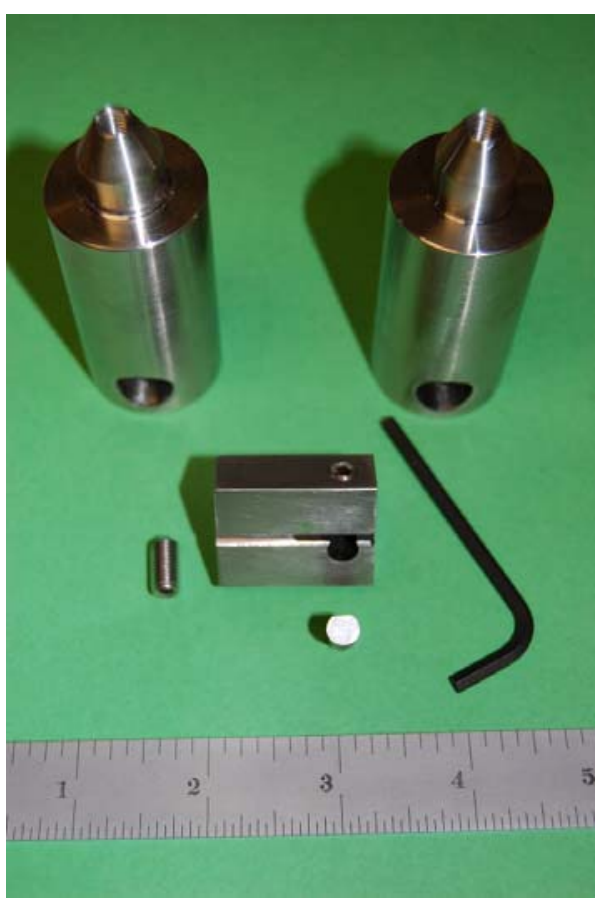

Figure 3. Wedge-Opening-Load Specimen Showing Allen Wrench, Bolt for Loading the Specimen, and Grips for Unloading the Specimen on Mechanical Test Machine. 


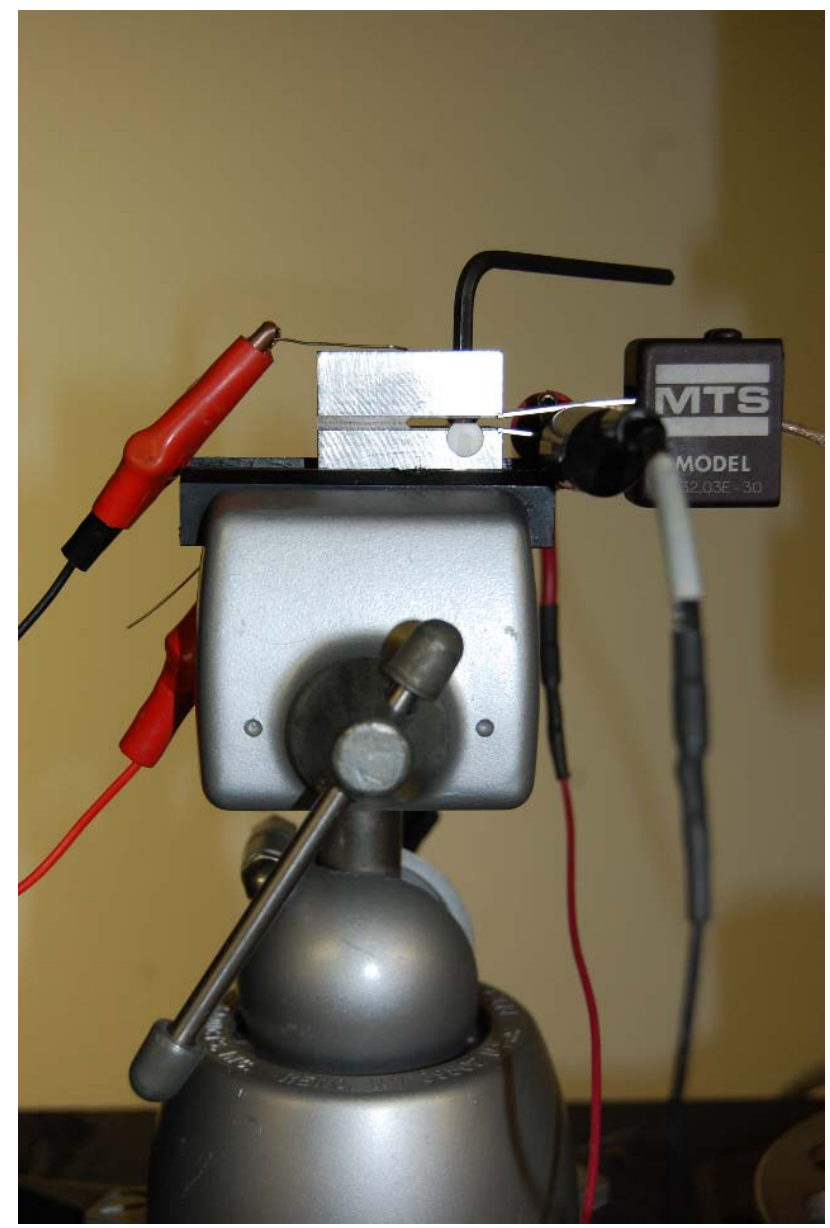

Figure 4. Wedge-Opening-Load Specimen Showing Bolt Loading Technique with Allen Wrench, COD Gage, and Leads For Crack Length Measurement.

\section{TRITIUM CONTENTS AND FOR LABORATORY INVENTORY REQUIREMENTS AND ENVIRONMENTAL RELEASE ESTIMATES}

Two tritium charging runs were conducted for SRNL during October of 2012 and November of 2012. The samples are listed in Section III above. In order to satisfy SRNL tritium inventory requirements and to provide future estimates of tritium release during testing the total tritium dissolved in the samples after charging, a tritium diffusion calculation was conducted (9-10). The calculations were performed using the Diff computer program (11). The Diff computer program will also be used for estimating tritium off-gassing rates once the samples are transferred to SRNL and tested and a more complete exposure history is defined. For the off-gassing calculation, the procedure described in Reference 12 will be used. 
There were seventy-five arc-shaped stainless steel coupons stacked together for each charging assembly for the two tritium charging runs conducted for SRNL on the Tritium Loading Line during October and November, 2012 (Figures 5-6). The samples were stacked on a stainless steel assembly shown in Figure 6. The assembly consists of two stainless steel caps 1.94" in diameter by .170" thick and six .170" diameter x 5.5” long rods and a .75 ”long x .5” wide x .170" thick handle. The tritium charging was conducted at temperature of $350^{\circ} \mathrm{C}$ and a fill pressure at temperature of approximately 5000 psia.

Calculations were performed that resulted in the following findings (9-10) that will be used for inventory control of the samples stored in the laboratory: For the first charging run, the total tritium content for the samples and charging assembly was calculated to be 1908 Curies. The seventy-five samples have a tritium content of 19.3 Curies each for a total of 1449 Curies. The samples are stacked on a stainless steel assembly consisting of two caps, 6 rods and a handle. The stainless steel assembly has a tritium content of 459 Curies. For the second tritium charging run conducted for SRNL during November of 2012. The total tritium content for the samples and charging assembly was calculated to be 1888 Curies. The seventy-five samples have a tritium content of 19.1 Curies each for a total of 1432 Curies. In this case, the stainless steel assembly has a tritium content of 456 Curies.
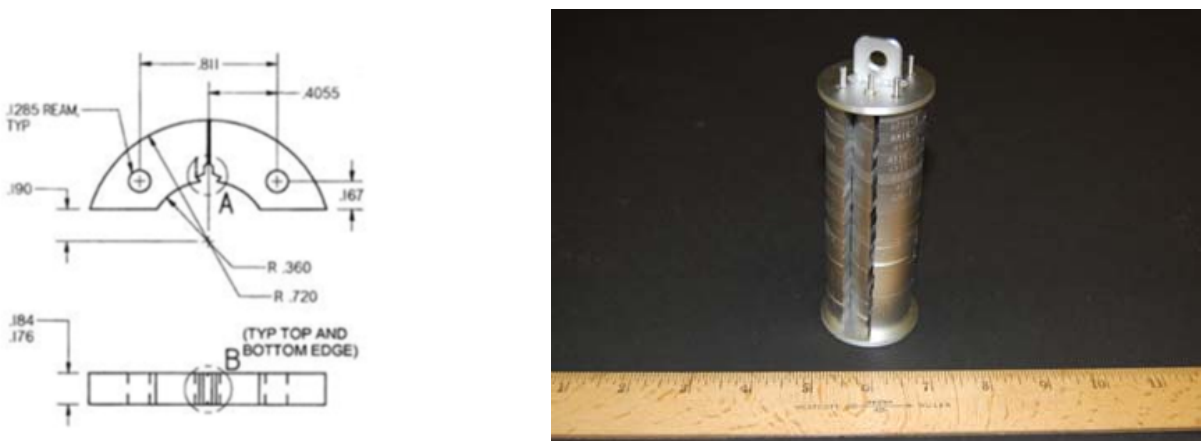

Figure 5. Seventy-Five Arc-Shaped Stainless Steel Coupons (on left) Stacked onto Tritium Charging Assembly in Three Columns (on right).

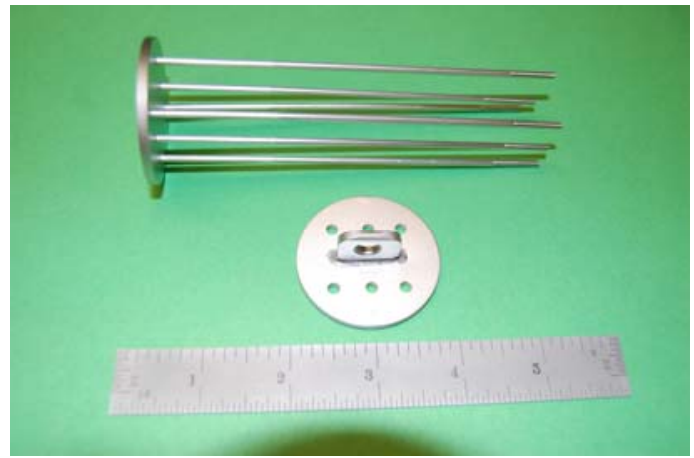

Figure 6. Tritium Charging Assembly Show Top and Bottom Caps and Six Rods 


\section{CRACKING THRESHOLDS AND FRACTURE TOUGHNESS PROPERTIES OF TRITIUM-CHARGED-AND-AGED STAINLESS STEELS}

A report entitled "Cracking Thresholds and Fracture Toughness Properties of Tritium-Charged-and-Aged Stainless Steels” was presented at the 2012 International Hydrogen Conference and submitted for publication in the conference proceedings (1314). Cracking thresholds and fracture toughness properties were measured for hydrogen and tritium pre-charged Types 304L and 21-6-9 stainless steels. The purpose of the experiments was to measure the effect of decay helium on the fracture properties of stainless steels and to compare sustained-load cracking thresholds with rising-load fracture toughness values. Sustained-load cracking threshold tests were conducted by step-loading and holding tritium pre-charged samples at constant loads until crack extension was detected. Rising-load fracture toughness values were measured using ASTM E1820. The results show that while both cracking thresholds and fracture toughness values decreased with increasing 3He content (Fig. 7), cracking thresholds were lower.

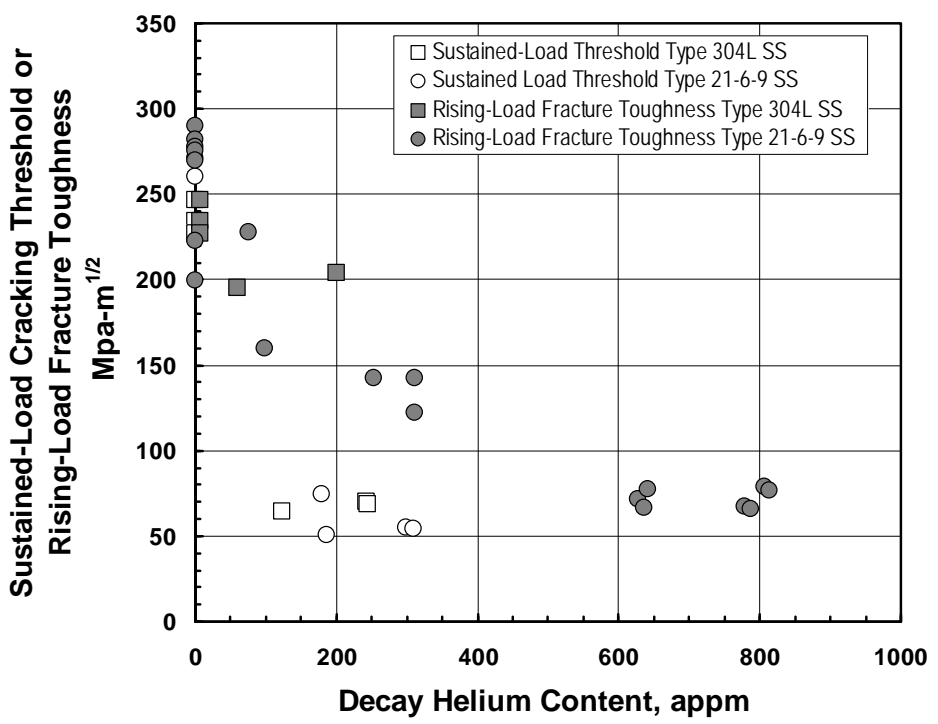

Figure 7. Effect of Decay Helium Content on Sustained-Load Cracking Thresholds and Rising Load Fracture Toughness Values.

The results of this study have important implications for tritium storage vessels. First, the results indicate that the threshold for tritium-induced cracking depends on the age of a vessel and its exposure history to tritium. During service, the vessel will age and become more embrittled with time because of tritium dissolution, diffusion, and radioactive decay. The effect of tritium and decay helium on cracking threshold and fracture 
toughness (Fig. 7) means that tritium vessels may become susceptible to subcritical cracking and delayed failure. Cracking threshold values like those shown in Figure 7 are needed for establishing safe lifetimes for vessels in tritium service. In this study, sustained-load cracking thresholds were lower than rising-load cracking thresholds.

The results suggest that the difference between sustained-load cracking thresholds and rising-load cracking thresholds is not due to problems associated with detecting the actual point of crack extension. Sustained-load thresholds are still lower than rising-load thresholds even after adjustments are made to the rising-load data to account for the actual point of crack extension. Rather, the results suggest that sustained-load cracking thresholds are lower because of greater tritium diffusion and redistribution during the cracking process. Sustained-load tests apparently have sufficiently longer loading times for greater tritium redistribution and concentration near the crack tip. The higher crack tip tritium concentration causes a lower cracking threshold.

Because of the uncertainties associated with the establishing hold times that are sufficiently long enough for the tritium-induced cracking process, the sustained-load testing protocol needs further work. It may be possible to refine the test protocol using hydrogen pre-charged samples so that fewer samples would be needed for the tritium tests. Alternatively, a correlation between long-time sustained-load tests results and the short-term rising-load test results could be developed. These will be subjects of future investigations.

The complete presentation is depicted in Figure 8. 


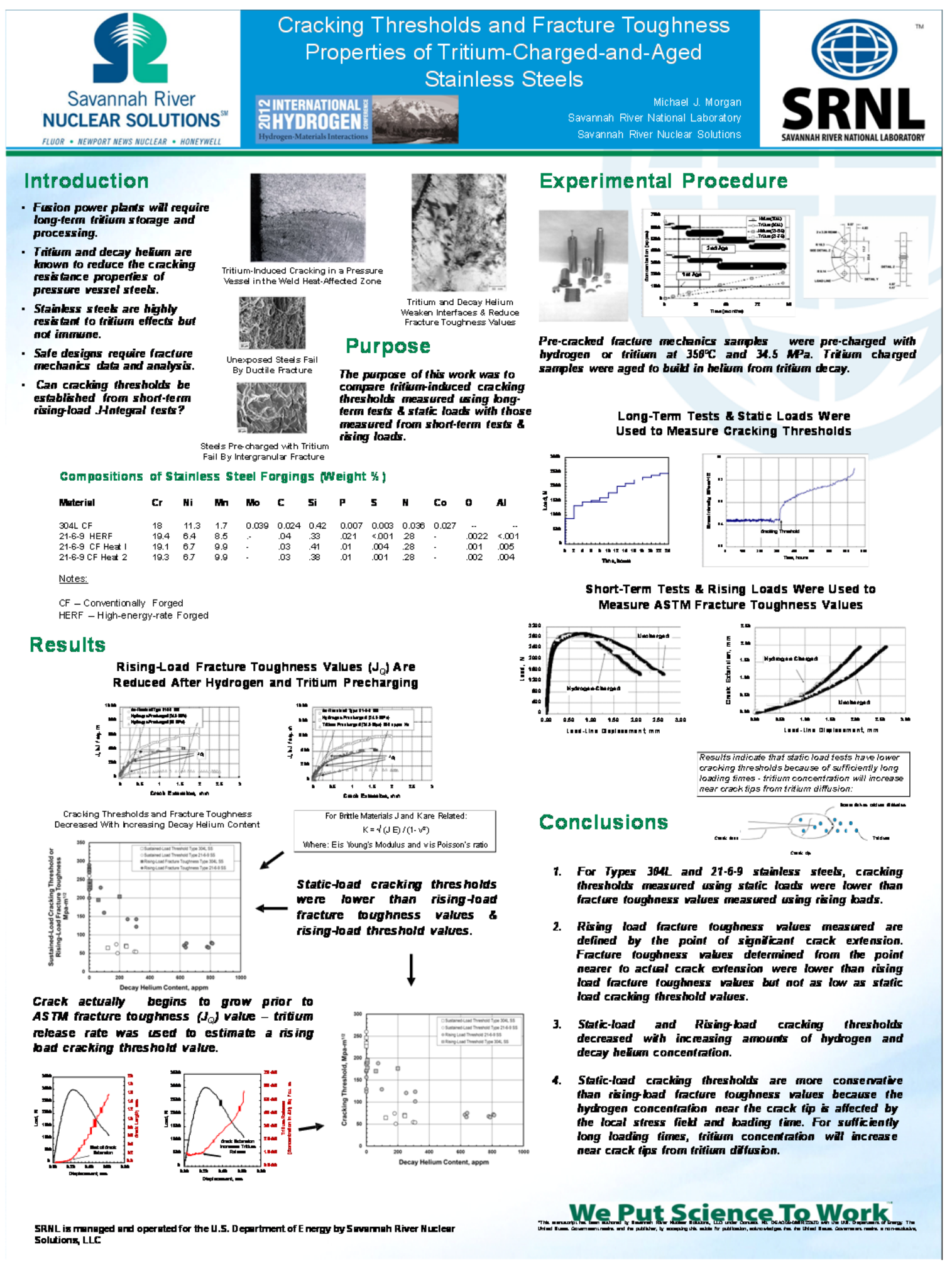

Figure 8. 2012 International Hydrogen Conference Presentation "Cracking Thresholds and Fracture Toughness Properties of Tritium-Charged-and-Aged Stainless Steels”. 


\section{THE EFFECTS OF HYDROGEN, TRITIUM, AND HEAT TREATMENT ON THE DEFORMATION AND FRACTURE TOUGHNESS PROPERTIES OF STAINLESS STEELS}

A report on the effects of hydrogen, tritium, and heat treatment on the deformation and fracture toughness properties of stainless steels was also presented at the 2012 International Hydrogen Conference and submitted for publication in the conference proceedings (15-16). In this work, the deformation and fracture toughness properties of forged stainless steels pre-charged with tritium were compared to the deformation and fracture toughness properties of the same steels heat treated at $773 \mathrm{~K}$ or $873 \mathrm{~K}$ and precharged with hydrogen (Fig. 9). Forged stainless steels pre-charged with tritium exhibit an aging effect: Fracture toughness values decrease with aging time after pre-charging because of the increase in concentration of helium from tritium decay. The study showed that forged stainless steels given a prior heat treatment and then pre-charged with hydrogen also exhibit an aging effect: Fracture toughness values decrease with increasing time at temperature. A microstructural analysis showed that the fracture toughness reduction in the heat-treated steels was due to patches of recrystallized grains that form within the forged matrix during the heat treatment (Fig. 10). The combination of hydrogen and the patches of recrystallized grains resulted in more deformation twinning. Heavy deformation twinning on multiple slip planes was typical for the hydrogencharged samples; whereas, in the non-charged samples, less twinning was observed and was generally limited to one slip plane. Similar effects occur in tritium pre-charged

steels, but the deformation twinning is brought on by the hardening associated with decay helium bubbles in the microstructure. The complete presentation is depicted in Figure 11. 


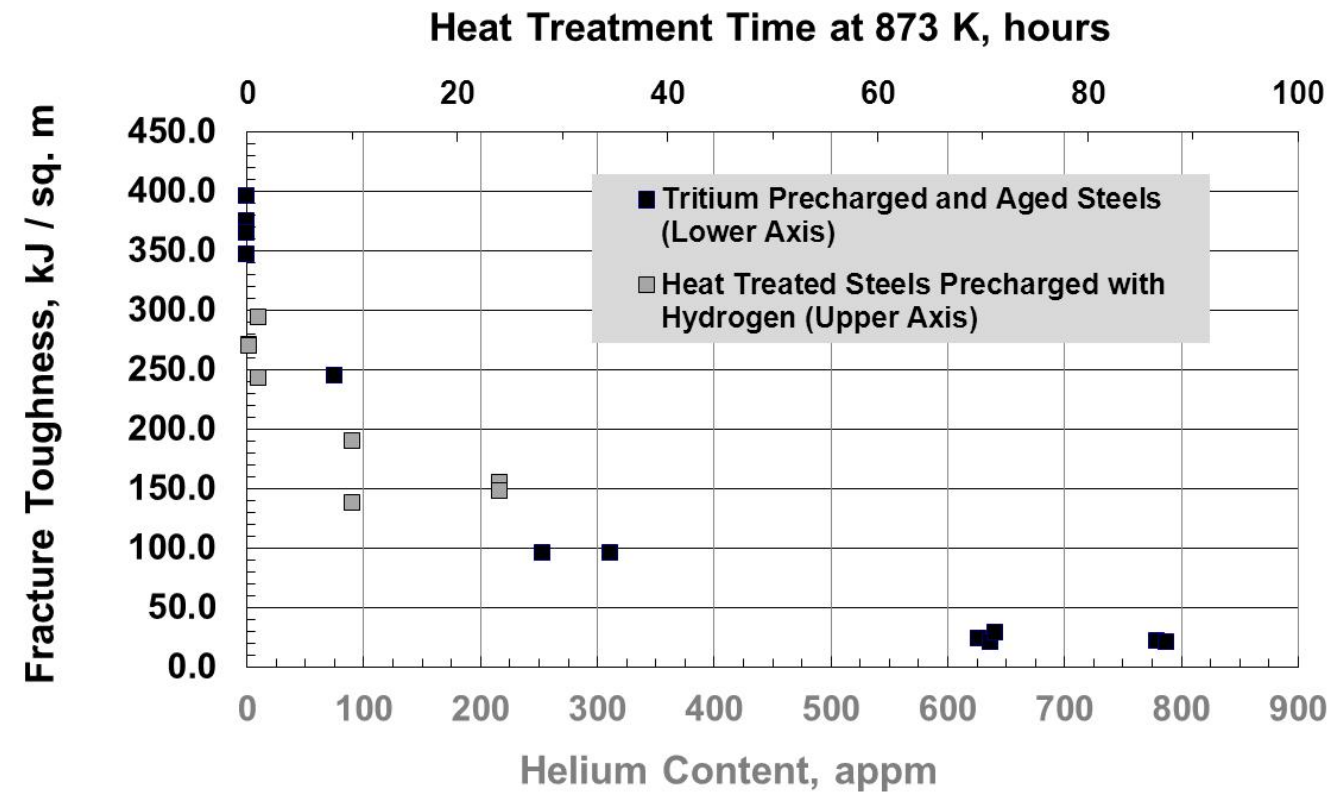

Figure 9. Hydrogen-Precharged Steels Given a Prior Heat Treatment at $873 \mathrm{~K}$ Show SimilarFracture Toughness Reductions As Tritium-Precharged Samples.
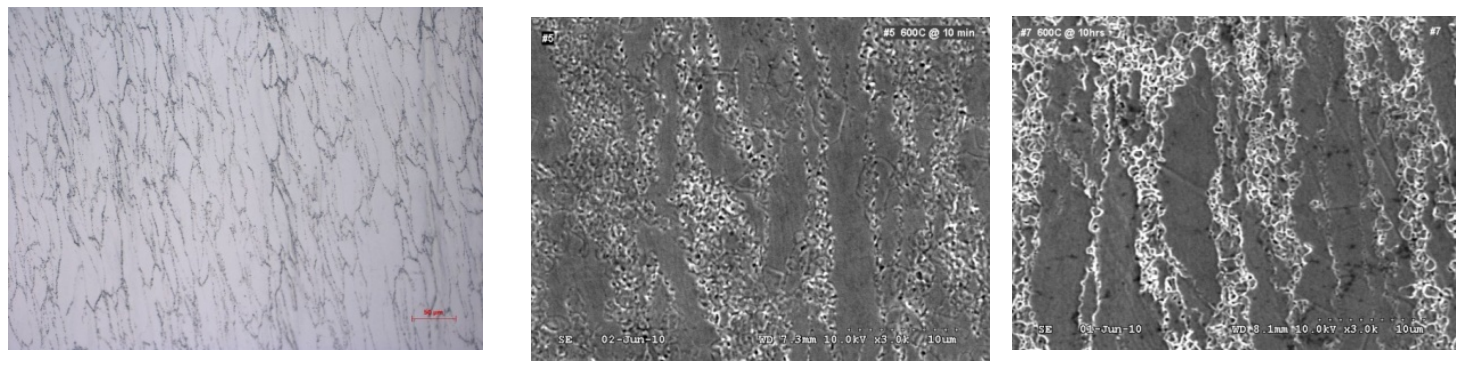

Figure 10. Microstuctures of (a) As Forged Steel (optical image); (b) Heat-Treated for 10 Min. at $873 \mathrm{~K}$ (Scanning Electron Microscope Image); and (c) Heat Treated for 10 Hours at $873 \mathrm{~K}$ (SEM Image). 


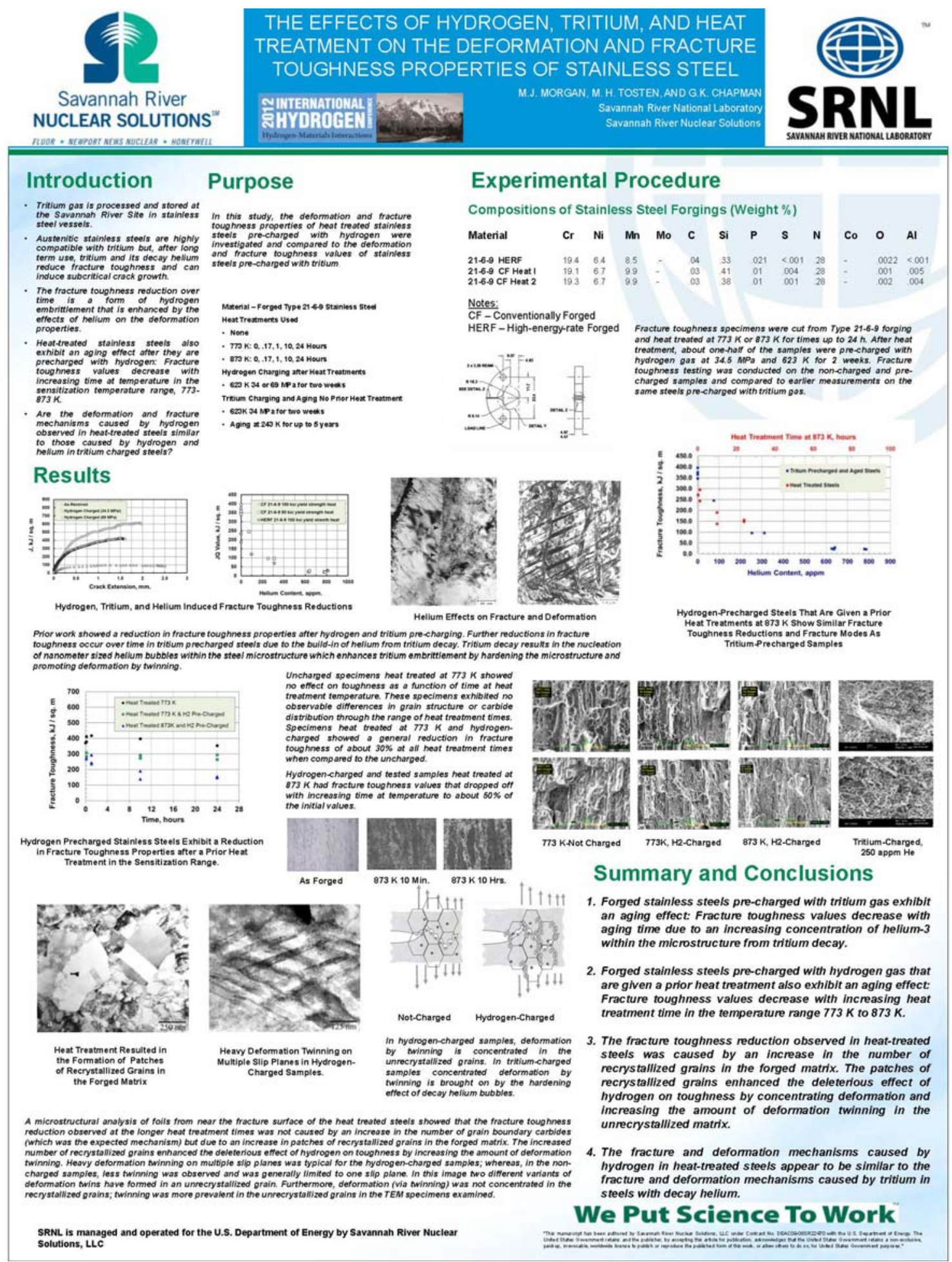

Figure 11. 2012 International Hydrogen Conference Presentation on "The Effects of Hydrogen and Tritium and Heat Treatment on the Deformation and Fracture Toughness Properties of Stainless Steels. 


\section{SUMMARY}

New experimental programs designed to measure the effects of the forging process and materials on tritium compatibility are underway. The programs are designed to investigate the effects of hydrogen, tritium, and decay helium on the fracture toughness properties of reservoir forgings. These programs will be unique because the effects of tritium on actual reservoir forgings have not been measured until now. Samples have been cut from a variety of forgings and exposed to hydrogen or tritium gas. Samples will be aged for up to five years and fracture mechanics tests conducted to measure the effect of decay helium on properties. Tests will be conducted in air until facilities are available for testing in high-pressure hydrogen gas. The specific objectives of each program are:

1. For Type 316L Cup forgings, measure the effect of crack orientation and in-part fracture toughness property variation.

2. For Type 304L Block forgings, measure fracture toughness properties for lowyield strength and high-yield strength forgings.

3. For Type 21-6-9 Brick forgings, measure effect of crack orientation and in-part fracture toughness variability. Also investigate sample size and geometry effect of fracture toughness and compare results with measurements conducted at LANL, SNL, and AWE.

4. For Type 304L forgings, measure effect of forging process, forging temperature, and prior anneal on fracture toughness properties. Also, measure forging strain rate effects on toughness and tritium compatibility by measuring toughness for forgings made using HERF, Mechanical Press, Screw Press, and Hydraulic Press.

5. For Type 21-6-9 Brick and Type 304L Block forgings, measure sustained load cracking thresholds using bolt-loaded specimens held in high pressure hydrogen environments.

\section{REFERENCES}

1. Michael J. Morgan and Glenn K. Chapman, "Forging Effects on Fracture Toughness Properties of Tritium-Charged-and-Aged Stainless Steels - Program Plan and Initial Results”, SRNL-TR-2011-00321, November 2011.

2. SRNL-L4400-2012-00027, SRNL Correspondence from M.J. Morgan to T.S. McGee, 10-9-2012, “SRNL Data Sheet Tritium Charging Conditions Run 2012-1”.

3. SRNL-L4400-2012-00031, SRNL Correspondence from M.J. Morgan to G.D. Levi, 11-8-2012, "SRNL Data Sheet Tritium Charging Conditions Run 2012-2” 
4. M. J. Morgan and G. K. Chapman, "Cracking Thresholds and Fracture Toughness Properties of Tritium-Charged-and-Aged Stainless Steels”, WSRC-TR-2010-00393, Savannah River National Laboratory, Washington Savannah River Company, Savannah River Site, Aiken, SC, December, 2010.

5. M. J. Morgan and D. Lohmeier, "Threshold Stress Intensities and Crack Growth Rates In Tritium-Exposed HERF Stainless Steels", Hydrogen Effects on Material Behavior, N. R. Moody and A. W. Thompson, eds., pp. 459-468, TMS, Warrendale, PA (1990).

6. M. J. Morgan and M. H. Tosten, "Tritium and Decay Helium Effects on Cracking Thresholds and Velocities in Stainless Steels”, Fusion Technology, Vol. 39, pages 590-595, 2001.

7. ASTM E 1681-03 "Standard Test Method for Determining Threshold Stress Intensity Factor for Environmental Assisted Cracking of Metallic Materials”, 2008 Annual Book of ASTM Standard Volume 3.01 Metals-Mechanical Testing; Elevated and Low-Temperature Tests; Metallography, American Society for Testing and Materials, 2008.

8. Conceptual Design Package, Project Y-642, Enhanced Fracture Toughness Tester, 774-A, M-CDP-A-00014 Rev.0, prepared by William P. Lenartz, 9-21-2011.

9. SRNL-L4000-2012-00021, SRNL Correspondence from M.J. Morgan to J.M. Shappell, "Tritium Content in Samples and Charging Assembly - 1st Tritium Charging Run”, 11-1-2012.

10. SRNL-L4400-2012-00032, SRNL Correspondence from M.J. Morgan to J. M. Shappell, "Tritium Content in Samples and Charging Assembly - 2nd Tritium Charging Run”, 11-27-2012.

11. K. E. Kain, “Finite-Difference Program for Hydrogen Diffusion”, DP-1738 March, 1987.

12. Calculation S-CLC-A-00147 "Tritium Content and Off-Gassing Rates for Samples Used in the Enhanced Fracture Toughness Tester" by Michael Morgan.

13. M. J. Morgan, "Cracking Thresholds and Fracture Toughness Properties of TritiumCharged-and-Aged Stainless Steels", Submitted for Publication in the Proceedings of the 2012 International Hydrogen Conference, ASME, September 9-12, Moran, Wyoming.

14. M. J. Morgan, "Cracking Thresholds and Fracture Toughness Properties of TritiumCharged-and-Aged Stainless Steels”, SRNL-STI-2012-12-00531. 
15. M. J. Morgan, M.H. Tosten, and G. K. Chapman, "The Effects of Hydrogen, Tritium, and Heat Treatment on the Deformation and Fracture Toughness Properties of Stainless Steel", Submitted for Publication in the Proceedings of the 2012 International Hydrogen, ASME, September 9-12, Moran, Wyoming.

16. M. J. Morgan, M.H. Tosten, and G. K. Chapman, "The Effects of Hydrogen, Tritium, and Heat Treatment on the Deformation and Fracture Toughness Properties of Stainless Steel”, SRNL-STI-2012-12-00532. 